\title{
Road Feature Extraction from LANDSAT-8 and ResourceSat-2 Images
}

\author{
S. Lenin Kumar Reddy ${ }^{\star}, 1$ C. V. Rao ${ }^{1}$, and P. Rajesh Kumar ${ }^{2}$ \\ ${ }^{1}$ Technology and Innovation, MSA, National Remote Sensing Centre (NRSC), 500 037, India \\ ${ }^{2}$ Dept. of Electronics and Communication Engg., Andhra University College of Engineering, 530 003, India
}

Received 10 July 2020; accepted 2 June 2021; published 4 July 2021.

\begin{abstract}
This paper presents a methodology of road feature extraction from the different resolutions of Remote Sensing images of Landsat- 8 Operational Lander Image (OLI) and ResourceSat- 2 of Linear Imaging Self Sensor-3 (LISS-3) and LISS-4 sensors with the spatial resolutions of $15 \mathrm{~m}, 24 \mathrm{~m}$, and $5 \mathrm{~m}$. In the methodology of road extraction, an index is proposed based on the spectral profile of Roads, also involving Morphological transform (Top-Hat or Bot-Hat) and Markov Random Fields (MRF). In the proposed index, Short Wave Infrared (SWIR) band has a significant role in the detection of roads from sensors, and it is named Normalized Difference Road Index (NDRI). To enhancement of features from the index, Bot-Hat transforms used. To segment the road features from this image, MRF used. The methodology is performed on the OLI, LISS- 3 and LISS-4 images, and presented with results.
\end{abstract}

Keywords: Road Index, SWIR, NDRI, Bot-Hat transform, Markov Random Fields, LISS-3, OLI

Citation: S. Lenin Kumar Reddy, C. V. Rao, P. Rajesh Kumar, (2021), Road Feature Extraction from LANDSAT-8 and ResourceSat-2 Images, Russ. J. Earth. Sci., Vol. 21, ES3006, 10.2205/2021ES000772.

\section{INTRODUCTION}

Road feature extraction from the Remote Sensing images has a significant role in map update and monitoring the disasters at regular intervals. $\mathrm{Au}-$ tomatic road extraction from remote sensing images is an ever-challenging task due to image conditions changes (like seasonal, atmospheric, sensor, etc.). This paper is an extension work of [Reddy et al., 2019] focused on the extraction of roads whose road width is greater than $25 \mathrm{~m}$ (Freeways). Very High Resolution (VHR) images are useful for linear feature extraction, even street roads can extract, but due to Temporal Resolution (TR) and swath, it is not feasible at regular interval [Maselli et al., 2019] monitoring and update. The digitization of roads by Manual is time and cost-effective. In this paper, they were focusing on the extraction of roads from the various Spatial Resolutions (SR) remote sensing images.

The proposed index [Reddy et al., 2019] for detection of roads from Landsat- 8 Operational Lander Imager (OLI) is extended to ResourceSat-2 (RS-2) images with minor modification. One widely used method for feature extraction from OLI images is normalized difference indices, which is the Normalized Difference Vegetation Index (NDVI) for vegetation, NDWI for water $[X u, 2007]$ and NDBI for

\footnotetext{
${ }^{*}$ Corresponding author: leninkumar438@gmail.com
}

built-up area [Bhatti and Tripathi, 2014; Garg et al., 2016; Zha et al., 2003]. All these indices are very useful for feature extraction from Remote Sensing images. In the way, for road feature extraction from WorldView-2 (WV-2) images, an index proposed [Shahi et al., 2015] named Road Extraction Index (REI), and it made by NIR2 $(860-1040 \mathrm{~nm})$ and Blue (450-510 $\mathrm{nm}$ ) bands of WV-2. Vegetation and Water body feature extraction from RS-2 images also able to extract by the indices, i.e., NDVI and NDWI. Vegetation features are obtained from Linear Imaging Self Sensor (LISS)-4 images by using the NDVI index [Verma et al., 2016], employing the decision tree model. Form the literature, and it understood that index-based feature extraction from remote sensing images has vast importance, and accuracy was more. This paper also shows an index based road feature extraction is feasible for different SR of OLI (15 m), LISS-3 $(24 \mathrm{~m})$, and LISS-4 $(5 \mathrm{~m})$. Also, a small test case performed on Sentinel-2 (S-2) with a 10 m SR image for the same.

In this paper, an index based road extraction from LR images of OLI and HR images of RS-2. The proposed methodology of road feature extraction from the various resolutions of images includes road index based on suitability and availability of bands with Morphological transform (Top-Hat or Bot-Hat) and Markov Random Fields (MRF) [Reddy et al., 2019]. To enhance the road features from 
an index image, Morphological operators used. To segment the road features from this image, MRF used. The MRF model parameters mean and variance calculated using Maximum Likelihood Estimation with Expectation and Maximization [Dempster et al., 1977].

This paper organized as in section section 2 given analysis on the OLI and LISS-3 bands for the proposed index. The results of the mentioned sensor images presented with analysis in section section 3 .

\section{Proposed Methodology}

The proposed methodology depends on the index named Normalized Difference Asphalt Road Index (NDARI). It is proposed based on the reflectance of asphalt in the specific bands like NDVI, where the slope is very high for vegetation from all the bands.

The proposed index depends on the spectral reflectance of asphalt in all the bands from OLI. Roads built with the different material combinations have a specific signature at bands of wavelengths. Mostly the asphalt roads are made with a mix of gravel, asphalt, bitumen, and some form of carbon type material [Herald and Roberts, 2005], and in [Singh and Garg, 2013] presented an analysis on various pavement roads and their reflectance variations with age.

\subsection{OLI and ResourceSat-2}

OLI sensor has the eight multispectral bands with Spatial Resolution (SR) of $30 \mathrm{~m}$, and wavelength ranges are in visible and infra-red and one panchromatic band with SR of $15 \mathrm{~m}$ given in Table 1 . Road feature extraction from the OLI images [Reddy et al., 2019] using the Normalized Difference Road Index (NDRI) with morphological transform and MRF. The indices proposed for road feature extraction from OLI are NDARI 1 and NDARI 2. The results obtained from these indices are combined and are called NDRI.

$$
\text { NDARI } 1=\frac{\text { NIR }- \text { Blue }}{\text { NIR }+ \text { Blue }}
$$

and

$$
\text { NDARI } 2=\frac{\text { SWIR }- \text { Blue }}{\text { SWIR }+ \text { Blue }}
$$

This methodology extended to apply for the ResourceSat-2 (RS2). It has two sensors, namely LISS-3 with SR of $24 \mathrm{~m}$ and LISS-4 sensor with SR of $5 \mathrm{~m}$. LISS- 3 has four bands as well as LISS- 4 has three bands and given in Table 2 with their wavelength ranges.

The bands in RS2 (B2, B3, and B5) are approximately matching with OLI sensor bands wavelengths, and LISS-3 bands, except the NIR band, has good correlation with OLI images [Venkateswarlu et al., 2014]. The spectral reflectance of Built-up, roads, Vegetation, and water features from the OLI and LISS-3 images shown in Figure 1 and observed that the features in both sensors are maintaining the same trend. The bands associated with NDRI indices of OLI are Blue, NIR, and SWIR.

From Figure 1, NIR and SWIR bands of both sensors have a high spectral reflectance for asphalt road and urban features. By using these two bands, an index for detection of the Built-up area [Bhatti and Tripathi, 2014] includes roads and urban. To separate the roads and built-up areas, proposed a new index. The proposed indices NDARI for OLI include the band's Infra-Red images with Blue band combination. In the LISS-3 sensor, SWIR and NIR bands are available but not a blue band. Due to the nonavailability of the blue band from the LISS-3 sensor, chosen the Red band. It has the lowest asphalt reflectance and proper slope to differentiate roads from other features. The Green band is not able to differentiate roads from the water feature, due to an index (MNDWI) [Xu, 2007] is associated with SWIR and Green bands. Also, NIR and Green is with Water Ratio Index (WRI), well-defined for water index. Instead of a blue band, it can also use the red band and able to extract the road features from OLI but less. The modified indices for RS-2 are

$$
\text { NDARI } 1=\frac{\text { NIR }- \text { Red }}{\text { NIR }+ \text { Red }}
$$

The NDARI1 of RS-2 is also well-defined for the NDVI index [Parveen et al., 2016]. With the optimal threshold, roads can extract very limited but

Table 1: LANDSAT-8 (OLI) Sensors and Band Names

\begin{tabular}{lcc}
\hline Band Name & $\begin{array}{c}\text { Wavelength } \\
(\boldsymbol{\mu m})\end{array}$ & SR $(\mathbf{m})$ \\
\hline Aerosol & $0.43-0.45$ & 30 \\
Blue & $0.45-0.51$ & 30 \\
Green & $0.53-0.59$ & 30 \\
Red & $0.64-0.67$ & 30 \\
NIR & $0.85-0.88$ & 30 \\
SWIR 1 & $1.57-1.65$ & 30 \\
SWIR 2 & $2.11-2.29$ & 30 \\
Panchromatic & $0.50-0.68$ & 15 \\
\hline
\end{tabular}

Table 2: Resourcesat-2 (RS-2) Sensors Bands

\begin{tabular}{lccc}
\hline Band Name & $\begin{array}{c}\text { Wavelength } \\
(\boldsymbol{\mu m})\end{array}$ & $\begin{array}{c}\text { LISS-3 } \\
\text { SR }(\mathbf{m})\end{array}$ & $\begin{array}{c}\text { LISS-4 } \\
\text { SR }(\mathbf{m})\end{array}$ \\
\hline B2 - Green & $0.52-0.59$ & 24 & 5 \\
B3 - Red & $0.62-0.68$ & 24 & 5 \\
B4 - NIR & $0.77-0.86$ & 24 & 5 \\
B5 - SWIR & $1.55-1.70$ & 24 & - \\
\hline
\end{tabular}




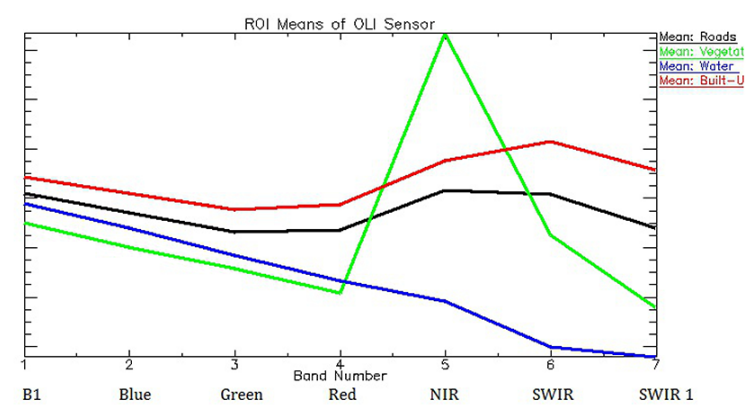

a)

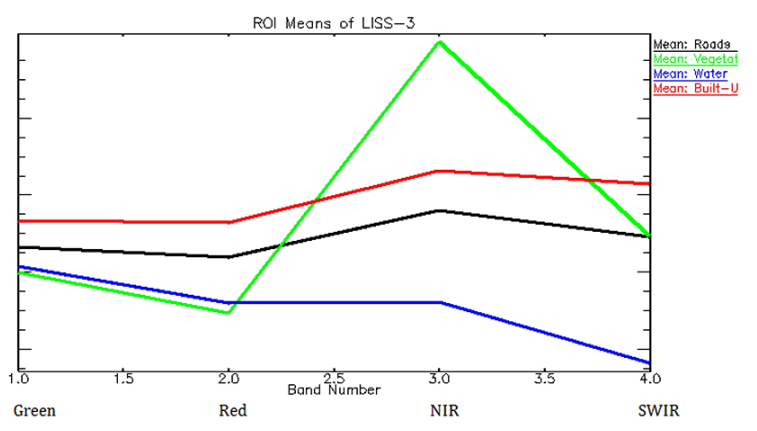

b)

Figure 1: Spectral plots of (a) OLI Image (Region of Interest) (b) LISS-3 Image (ROI).

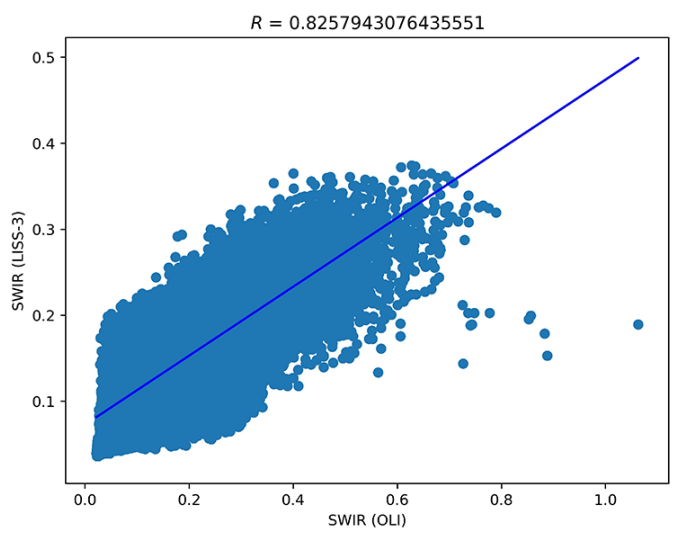

a)

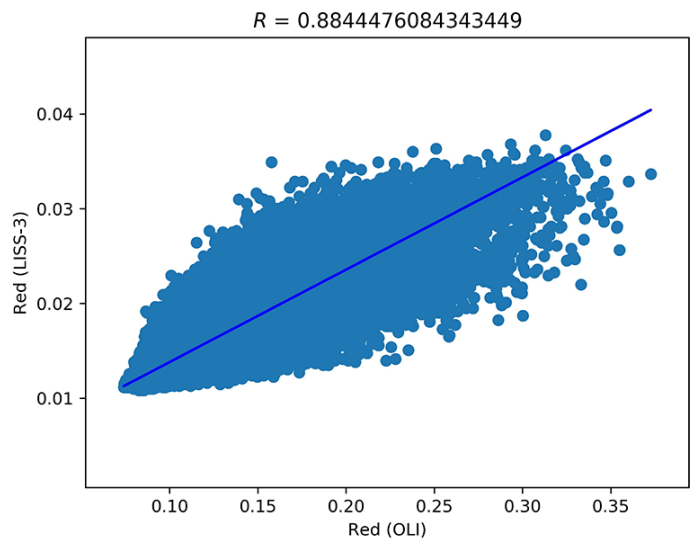

b)

Figure 2: Scatter plots of (a) SWIR bands (OLI (SWIR 1) vs. LISS-3) (b) Red bands (OLI vs. LISS-3).

not feasible as road index. Due to this, the NDAR1 index is not usable for RS-2 images. The second index NDARI2 is

$$
\text { NDARI } 2=N D R I=\frac{\text { SWIR }- \text { Red }}{\text { SWIR }+ \text { Red }}
$$

The NDARI2 index for RS-2, further referred to as NDRI only due to NDARI1 not exist as the road index. RS-2 has one more medium resolution sensor, i.e., LISS-4, has three bands (Green, Red, and NIR) only. The SWIR band used in this paper for the LISS- 4 sensor predicted band from the LISS- 3 sensor. The predicted SWIR band obtained by using the linear regression method [Anjaneyulu et al., 2019] using the LISS-3 sensor of the same date with the SR of $5 \mathrm{~m}$. The scatter plots of SWIR and Red bands between OLI and LISS-3 for ROI (OLI vs. LISS-3) are shown in Figure 2 and have an excellent correlation coefficient of R-value.

\subsection{Morphological Transform}

From the index, by using the optimal threshold can extract from OLI images [Soille and Pesaresi, 2002], but limited. For the enhancement of the index im- age, morphological transforms used. They are BotHat and Top-Hat. Bot-Hat is used to elevate the dark feature form the bright features with the structuring element and vice-versa for Top-Hat.

$$
\begin{aligned}
& \text { Top }- \text { Hat }=\mathrm{I}-(\mathrm{I} \circ \mathrm{B}) \\
& \text { Bot }- \text { Hat }=(\mathrm{I} \bullet \mathrm{B})-\mathrm{I}
\end{aligned}
$$

Where I represent index (NDRI) image and B is the structuring element.

\subsection{Markov Random Fields}

MRF model is [Krishnamachari and Chellappa, 1997], a stochastic model that depends on the neighboring information. It has vast importance in pattern recognition and image segmentation. MRF model is used to find the absent labels by using observation samples. In this letter, observation samples are taken from the Index (Bot-Hat transform applied on the index) by Otsu or optimal threshold as given in [Reddy et al., 2019]. 


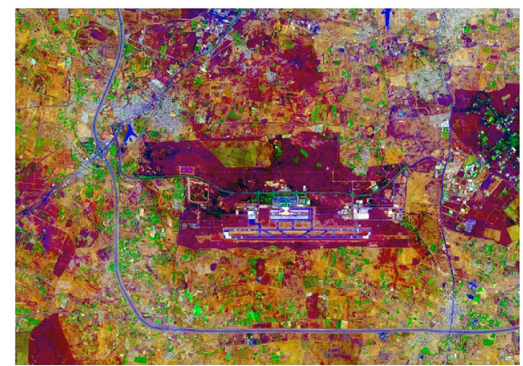

a)

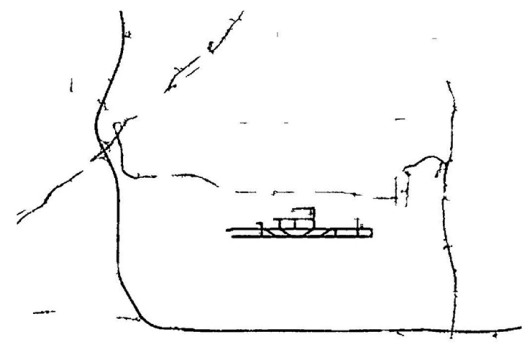

c)

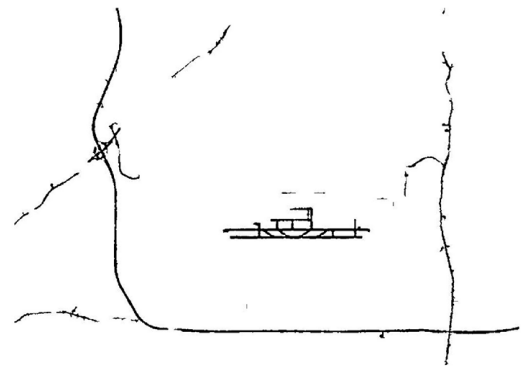

b)

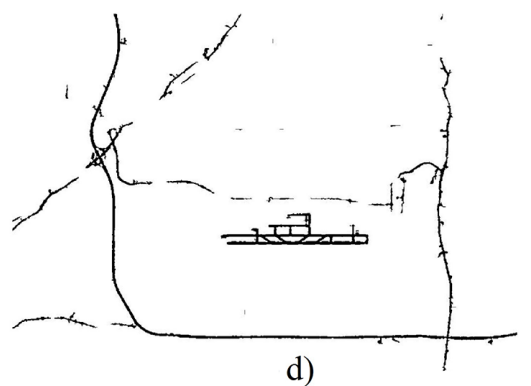

d)

Figure 3: (a) OLI (B762, 15m), RGIA and ORR are sub scenes of Hyderabad, India (b) NDARI1, (c) NDARI2, (f) NDRI (combined).

\section{Results and Analysis}

The experiments were performed by using proposed indices with MRF on OLI and RS-2 (LISS-3 and LISS-4) images and used in this paper. These sensors date of passes with path and row is given in Table 3. The chosen data covers the same area of Hyderabad, India. All the images mentioned in the paper are Top of Atmosphere (TOA) Reflectance corrected. RS-2 images are provided by the National Remote Sensing Centre (NRSC), ISRO.

Initially, the NDRI was proposed for OLI images and then extended to different Resolution images for LISS-3 $(24 \mathrm{~m})$ and LISS-4 $(5 \mathrm{~m})$. OLI of Blue, NIR, and SWIR bands are pan-sharpened with Panchromatic (B8) (SR is $15 \mathrm{~m}$ ). For OLI images road features are extracted by the proposed index NDRI (NDARI 1 and NDARI2), as presented in [Reddy et al., 2019] are shown in Figure 3 and Figure 4. In [Shahi et al., 2015], proposed an index for Roads extraction (i.e., REI) from WorldView-2 images. In REI used bands wavelengths are approximate matches with OLI bands wavelengths are NIR

Table 3: LANDSAT-8 (OLI) Sensors and Band Names

\begin{tabular}{lcc}
\hline Sensor & Date of Pass & Path/row \\
\hline OLI & 26 March 2018 & $144 / 048$ \\
LISS-3 & 25 March 2018 & $100 / 60$ \\
LISS-4 & 25 March 2018 & $100 / 61$ \\
Sentinel-2B & 25 March 2018 & - \\
\hline
\end{tabular}

and Blue. By using REI, roads are extracted from OLI images and shown in Figure 5. The REI is similar to NDARI 1, and also results are the same. But, by using the proposed methodology has more number of roads than REI. The length (in $\mathrm{km}$ ) of the extracted road using indices NDRI, REI, and Reference, which is drawn manually on the test image, given in Table 4 The accuracy of extracted roads with indices are presented in Table 5 and observed that the proposed method is producing better results.

Figure $3 \mathrm{a}$ is an OLI image with Bands 7, 5, 2, which covers an area of Rajiv Gandhi International Airport (RGIA), Hyderabad. In this image, consists of the roads freeways (National Highway) and Airport. By using NDARI 1 and NDARI 2 indices, roads extracted from OLI images shown in Figure $3 b$ and Figure $3 c$, respectively. The two indices of roads are combined, i.e., the resultant images of individual indices are added and shown in Figure 3d. Similarly, Figure 4a also consists of freeways of the same scene with different areas and extracted roads by the proposed method.

Table 4: Length (in km) of Extracted Road from OLI images

\begin{tabular}{lccc}
\hline & $\begin{array}{c}\text { Refere- } \\
\text { nce }\end{array}$ & $\begin{array}{c}\text { REI [Shahi } \\
\text { et al., 2015] }\end{array}$ & NDARI \\
\hline Figure 5 & 64 & 53 & 61 \\
Figure 6 & 81 & 71 & 75 \\
\hline
\end{tabular}




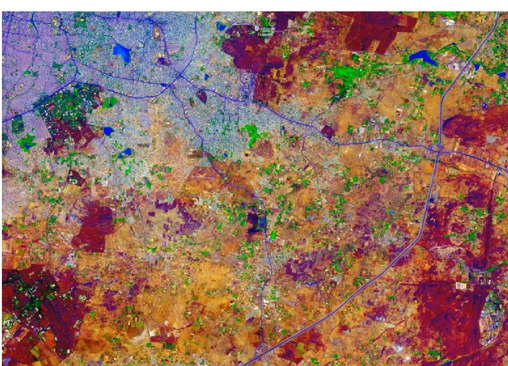

a)

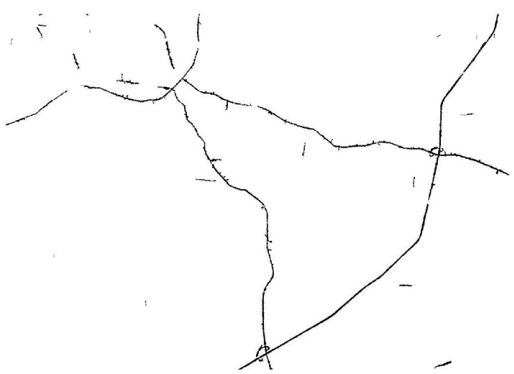

c)

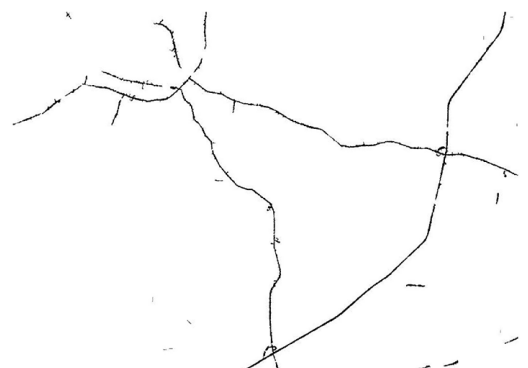

b)

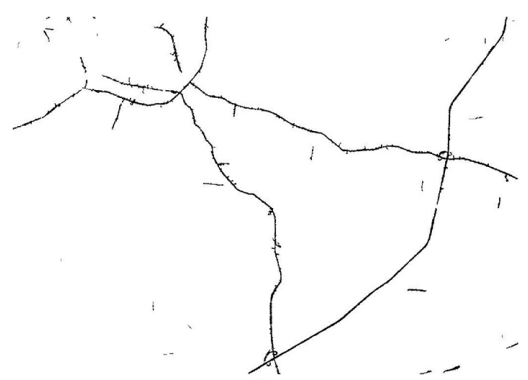

d)

Figure 4: (a) OLI (B762, 15m), NH65 and ORR are sub scenes of Hyderabad, India (b) NDARI1, (c) NDARI2, (f) NDRI (combined).

Table 5: Accuracy of Extracted Roads

\begin{tabular}{lccccc}
\hline \multirow{2}{*}{ Index } & \multicolumn{2}{c}{ REI [Shahi et } & al., 2015] & & \multicolumn{2}{c}{ NDARI } \\
\cline { 2 - 3 } \cline { 5 - 6 } & Figure 5 & Figure 6 & & Figure 5 & Figure 6 \\
\hline $\begin{array}{l}\text { Correct- } \\
\text { ness }\end{array}$ & 94.12 & 93.41 & & 95.51 & 94.69 \\
$\begin{array}{l}\text { Complete- } \\
\text { ness }\end{array}$ & 89.02 & 86.99 & & 90.62 & 87.71 \\
F1-score & 91.41 & 90.08 & & 93.00 & 91.07 \\
\hline
\end{tabular}

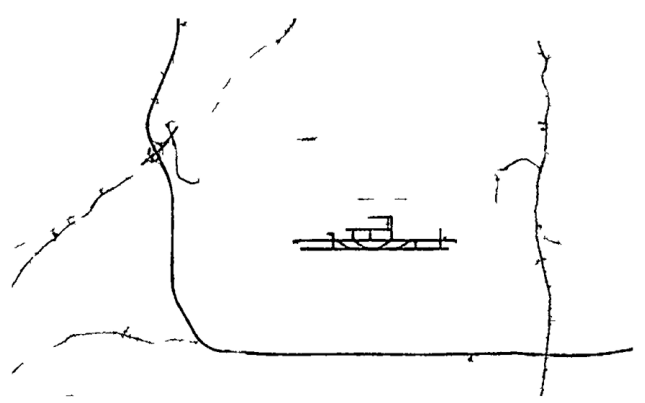

a)

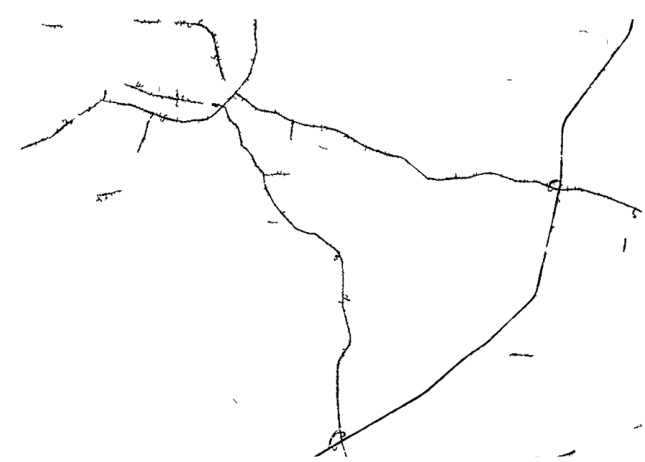

b)

Figure 5: Road extraction using REI [Shahi et al., 2015] (a) RGIA Airport and ORR, (b) NH65 are sub scenes of Hyderabad, India. 


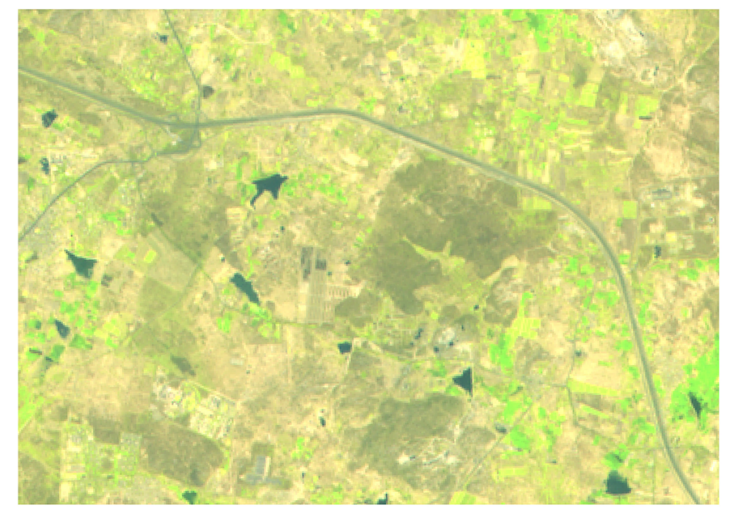

a)

Figure 6: (a) LISS-3 (B543, 24 m), (b) NDRI.

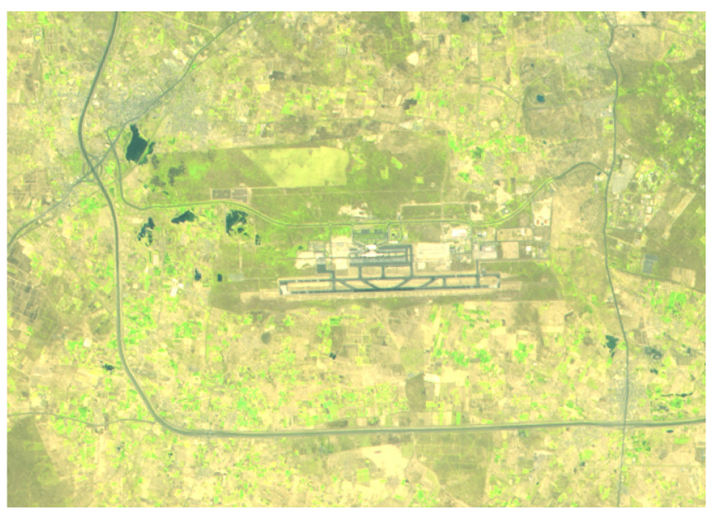

a)

Figure 7: (a) LISS-3 (B543, 24 m), (b) NDRI.

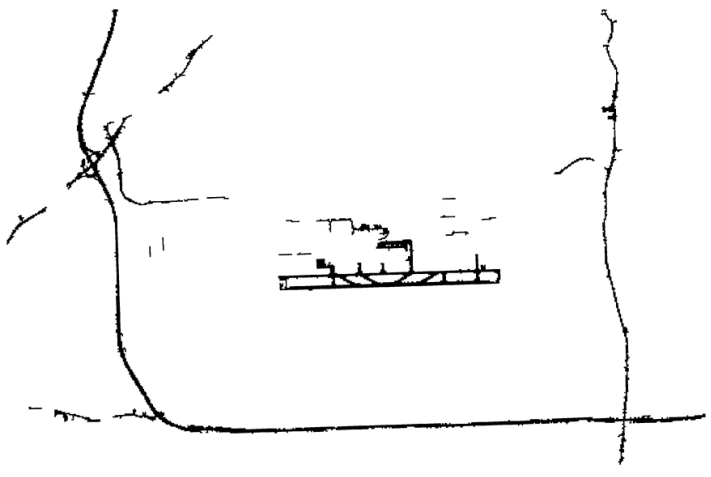

b)

b)

plied to HR images of the LISS-4 sensor with an SR of $5.8 \mathrm{~m}$, extracted the roads adequately can observe in Figure 8 and Figure 9. From results, we found that by increasing the SR of images, the extraction, i.e., the number of roads increased. From the images, it observed that the extraction of roads from LISS-4 images, increased due to the SR is high.

One test case on S-2 images conducted due to the SR is varied from $10 \mathrm{~m}, 20 \mathrm{~m}, 30 \mathrm{~m}$, and also matched the bands in both sensors [Costa et al., 2017]. S-2 bands comparison with OLI presented in [Costa et al., 2017; Dubes et al., 1990]. For S-2, the bands used in indices are like OLI (1) and (2). The bands involved from S-2 are Band 8A (NIR2, 0.848-0.881), SWIR (2.072-2.312) and Blue (0.439$0.535)$ bands. These bands are re-sampled to $10 \mathrm{~m}$ SR. From the figure-12, it observed that by increasing Spatial Resolution (i.e., from $24 \mathrm{~m}$ to $5 \mathrm{~m}$ ), road extraction quality increased. In the LISS-3 (24 m SR) image, four-lane roads combined due to resolution, road width of each lane is about greater than $7 \mathrm{~m}$ and detected as single road. From the Sentinel- 


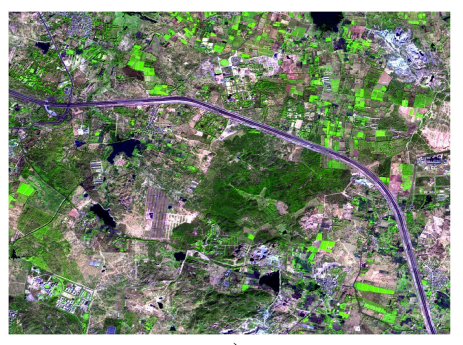

a)

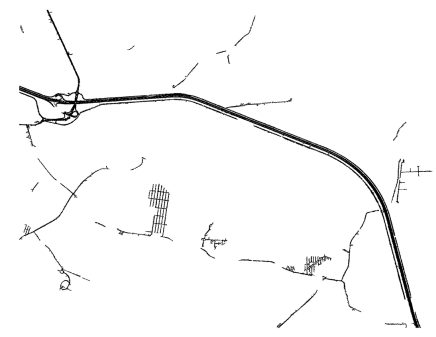

b)

Figure 8: (a) LISS-4 (FCC of B5, B4 and B3) image (5 m), (b) Road extracted using NDRI.

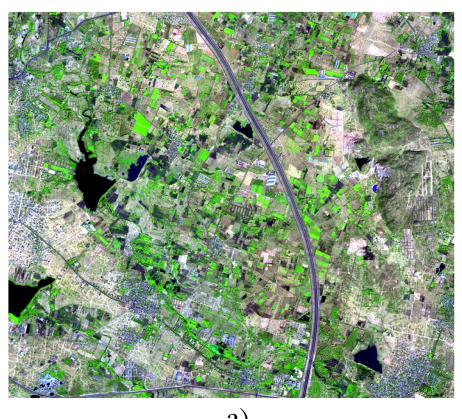

a)

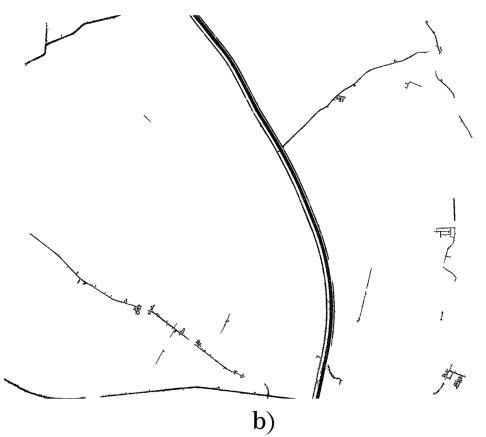

Figure 9: (a) LISS-4 (FCC of B5, B4 and B3) image (5 m), (b) Road extracted using NDRI.

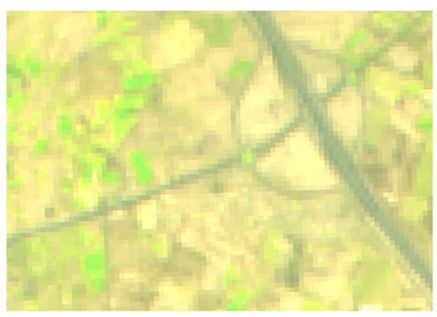

a)

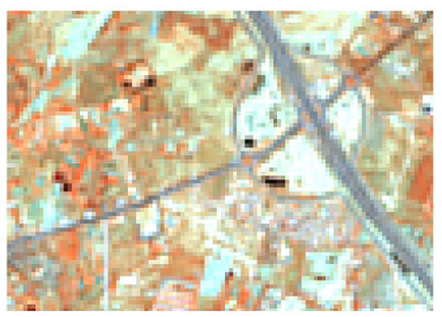

c)

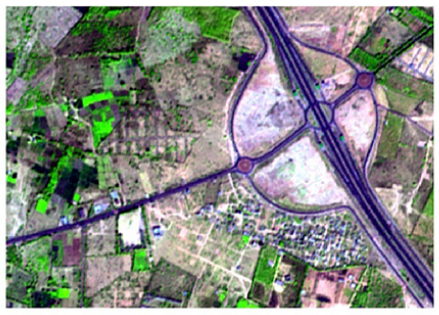

e)

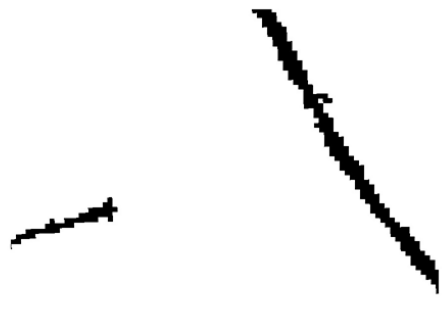

b)

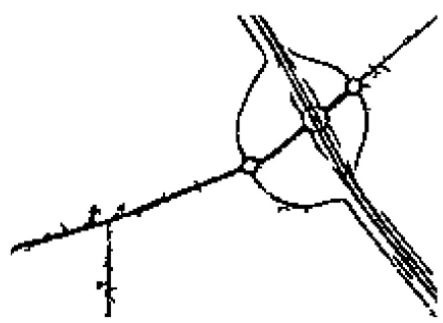

d)

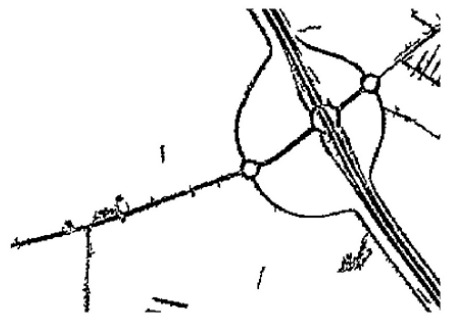

f)

Figure 10: (a) LISS-3 (B543, 24 m), (b) L3 road, (c) S2 (10 m) (SWIR, NIR, Blue), (d) S2 Roads, (e) LISS-4 (5 m), (f) L4 Road. 
2 (SR of $10 \mathrm{~m}$ ) image, each lane of road feature detected and minor missing due to an increase of SR from $24 \mathrm{~m}$ to $10 \mathrm{~m}$. Also, from the LISS-4 (SR of $5 \mathrm{~m}$ ) image, more roads are extracted shown in Figure 10 f than S-2 roads Figure $10 \mathrm{~d}$.

\section{Conclusion}

In this paper, an index proposed for the extraction of roads from various spatial resolutions of OLI (15 m), Sentinel-2 (10 m), LISS- 3 (24 m), and LISS$4(5 \mathrm{~m})$ images. The NDRI index is proposed based on the asphalt reflectance ranges in the entire wavelength range of bands present in the sensors. Asphalt has the highest reflectance in NIR and SWIR band ranges in all sensors. Based on this, two indices proposed where the availability of bands in the sensors. These two indices are for OLI and Sentinel2 and one index for ResourceSat- 2 images. The enhanced road features from the index obtained by the Morphological Transform. This image used for road features segmented by using the Markov Random Fields. From the results, it observed that the proposed index able to extract from the different spatial resolutions of images. SR from $30 \mathrm{~m}$ to $5 \mathrm{~m}$ increases, extraction of the number of roads also increased.

\section{ACKnOWledgements}

This research is funded and Resourcesat-2 data provided by the National Remote Sensing Centre (NRSC)/ISRO under the project (0606322EE303) titled "Development of geophysical and special processing algorithms from OCM and ResourceSat sensor data". We wish to express our sincere thanks to the Director, NRSC and R. V. G. Anjaneyulu, Head, SPD for their encouragement and guidance to publish the paper.

\section{REFERENCES}

Anjaneyulu, R. V. G., S. Suresh, M. K. Gali, C. V. Rao, and B. G. Krishna, Swir band synthesis at spatial resolution of liss-4 mx data using liss-3, in Journal of the Indian National Cartographic Association(INCA), vol. 38, pp. 914, INCA, 2019.

Bhatti, S. S., and N. K. Tripathi, Built-up area extraction using landsat 8 oli imagery, GIScience E Remote Sensing, 51(4), 445-467, doi:10.1080/15481603.2014.939539, 2014.

Costa, S., V. Santos, D. Melo, and P. Santos, Evaluation of landsat 8 and sentinel-2a data on the correlation between geological mapping and ndvi, in 2017 First IEEE International Symposium of Geoscience and Remote Sensing (GRSS-CHILE), pp. 1-4, doi:10.1109/GRSSCHILE.2017.7996006, 2017.

Dempster, A. P., N. M. Laird, and D. B. Rubin, Maximum likelihood from incomplete data via the em algorithm,
Journal of the Royal Statistical Society. Series B (Methodological), 39(1), 1-38, 1977.

Dubes, R. C., A. K. Jain, S. G. Nadabar, and C. C. Chen, Mrf model-based algorithms for image segmentation, in [1990] Proceedings. 10th International Conference on Pattern Recognition, vol. 1, pp. 808-814, doi:10.1109/ICPR.1990.118221, 1990.

Garg, A., D. Pal, H. Singh, and D. C. Pandey, A comparative study of ndbi, ndisi and ndii for extraction of urban impervious surface of dehradun [uttarakhand, india] using landsat 8 imagery, in 2016 International Conference on Emerging Trends in Communication Technologies (ETCT), pp. 1-5, doi:10.1109/ETCT.2016.7882963, 2016.

Herald, M., and D. A. Roberts, Spectral characteristics of asphalt road aging and deterioration: implications for remote-sensing applications., Applied optics, 44(20), 4327-4334, doi:10.1364/AO.44.004327, 2005.

Krishnamachari, S., and R. Chellappa, Multiresolution gauss-markov random field models for texture segmentation, IEEE Transactions on Image Processing, 6(2), 251267, doi:10.1109/83.551696, 1997.

Maselli, F., M. Chiesi, and M. Pieri, A new method to enhance the spatial features of multitemporal ndvi image series, IEEE Transactions on Geoscience and Remote Sensing, 57(7), 4967-4979, doi:10.1109/TGRS.2019.2894850, 2019.

Parveen, R., S. Kulkarni, and V. D. Mytri, Vegetation extraction based on spectral deviations using an irs-1c liss iii image, in 2016 International Conference on Wireless Communications, Signal Processing and Networking (WiSPNET), pp. 158-162, doi:10.1109/WiSPNET.2016.7566111, 2016.

Reddy, S. L. K., C. V. Rao, P. R. Kumar, R. V. G. Anjaneyulu, and V. M. Bothale, Automatic road feature extraction using $\mathrm{mrf}$ from landsat- 8 oli images, in 2019 IEEE Recent Advances in Geoscience and Remote Sensing : Technologies, Standards and Applications (TENGARSS), pp. 15-20, doi:10.1109/TENGARSS48957.2019.8976046, 2019.

Shahi, K., H. Z. Shafri, E. Taherzadeh, S. Mansor, and R. Muniandy, A novel spectral index to automatically extract road networks from worldview2 satellite imagery, The Egyptian Journal of Remote Sensing and Space Science, 18(1), 27-33, doi:https://doi.org/10.1016/j.ejrs.2014.12.003, 2015.

Singh, P. P., and R. D. Garg, Study of spectral reflectance characteristics of asphalt road surface using geomatics techniques, in 2013 International Conference on Advances in Computing, Communications and Informatics (ICACCI), pp. 516-520, doi:10.1109/ICACCI.2013.6637225, 2013.

Soille, P., and M. Pesaresi, Advances in mathematical morphology applied to geoscience and remote sensing, IEEE Transactions on Geoscience and Remote Sensing, 40(9), 2042-2055, doi:10.1109/TGRS.2002.804618, 2002.

Venkateswarlu, E., T. Sivannarayana, and K. V. Ratna Kumar, A comparative analysis of resourcesat-2 liss3 and landast-8 oli imagery, ISPRS - International Archives of the Photogrammetry, Remote Sensing and Spatial Information Sciences, XL-8, 987-989, doi:10.5194/isprsarchives-XL-8-987-2014, 2014. 
Verma, A. K., P. K. Garg, K. S. Hari Prasad, and V. K. Dadhwal, Classification of liss iv imagery using decision tree methods, ISPRS - International Archives of the Photogrammetry, Remote Sensing and Spatial Information Sciences, XLI-B8, 1061-1066, doi:10.5194/isprsarchives-XLI-B8-1061-2016, 2016.

$\mathrm{Xu}, \mathrm{H}$., Modification of normalised difference water index (ndwi) to enhance open water features in remotely sensed imagery, International Journal of Remote Sensing, 27(14), 3025-3033, doi:10.1080/01431160600589179, 2007.

Zha, Y., J. Gao, and S. Ni, Use of normalized difference built-up index in automatically mapping urban areas from tm imagery, International Journal of Remote Sensing, 24(3), 583-594, doi:10.1080/01431160304987, 2003. 